Riediger, M., Li, S.-C., \& Lindenberger, U. (2006). Selection, optimization, and compensation as developmental mechanisms of adaptive resource allocation: Review and preview. In J. E. Birren \& K. W. Schaie (Eds.), The handbooks of aging (Vol.2. Handbook of the psychology of aging, pp. 289-313). Amsterdam: Elsevier.

Thirteen

\title{
Selection, Optimization, and Compensation as Developmental Mechanisms of Adaptive Resource Allocation: Review and Preview
}

\author{
Michaela Riediger, Shu-Chen Li and Ulman Lindenberger
}

\section{Introduction}

Developmental psychology has investigated a multitude of developmental phenomena in different phases of the life span and in multiple domains of functioning. However, the resulting knowledge about human development in general and aging in particular continues to be fragmented, with relatively little connection across disparate strands of research and different research traditions (Baltes, Lindenberger, Staudinger, in press; Magnusson, 1996). Informed by work of others (e.g., Baltes, 1997; Freund \& Baltes, 2000; Marsiske et al., 1995), a central objective of this chapter is to use the conceptual framework of selection, optimization, and compensation (SOC; Baltes \& Baltes, 1990) as a tool for integrating research on adaptive resource allocation in life span development. In addition, we propose that the SOC framework helps open up promising research directions, especially if attempts are made to study the interplay of SOC mechanisms from a dynamic systems perspective.
In line with the scope of the SOC framework, the general approach taken in this chapter is inherently life span developmental (e.g., Baltes et al., in press). Our specific focus, however, is on later adulthood and old age. We start by introducing prominent contemporary conceptual frameworks of developmental regulation. In this context, we comment on the benefits and limitations of the resource metaphor for studying developmental regulation, given that resourceallocation mechanisms play a prominent role in all considered frameworks. Then we describe the SOC framework in more detail and conclude that this framework may serve as a heuristic tool for arriving at a more integrated picture of human development and aging. We elaborate this claim in two major ways. First, we make use of SOC to integrate evidence of a great variety of different resource allocation processes. Here, we selectively review conceptual approaches and recent empirical findings in two research domains: (a) motivational-volitional processes and (b) cognitive-sensorimotor functioning. 
Second, we illustrate the fecundity of the SOC framework for conceptualizing new research avenues. Here we emphasize the need for age-comparative assessments of SOC-related processes in single-person and multiple-person systems and on multiple levels of analyses (e.g., neuronal, behavioral, interpersonal). In conclusion, we advocate the use of formal models to further enhance the testability and predictive power of SOC mechanisms for describing, explaining, and modifying life span differences in the adaptive dynamics of resource allocation.

To avoid misunderstandings, the conceptual status and scope of SOC are clarified at the outset of this chapter. As a conceptual framework, SOC helps to synthesize existing and instigate novel strands of empirical research on developmental regulation. Thus, as is typical for conceptual cores of empirical research programs (e.g., Lakatos, 1970), the SOC framework is not amenable to direct testing (falsification) but serves to organize and guide an empirical research. However, as shown in the course of this chapter, the SOC framework leads to explicit and testable (falsifiable) predictions when it is brought to bear upon specific research questions and developmental domains, such as life span differences in selection mechanisms of cognitive processing. Furthermore, the conceptual scope of SOC is broader than represented in this chapter. Most importantly, SOC encompasses both mechanisms of resource generation and mechanisms of resource allocation (e.g., Krampe \& Baltes, 2003), whereas this chapter is restricted to the latter.

\section{Resource-Allocation Processes in Life Span Development}

During all phases of life, human development unfolds within the range of opportunities and constraints that biological, psychological, and contextual characteristics provide. Such opportunities and constraints for development can be subsumed under the general notion of resources. Resources are as diverse as the life domains and situations in which development takes place (for resource taxonomies illustrating this diversity, see Hobfoll, 1998; Read \& Miller, 1989; Wilensky, 1983). Individuals differ in their access to resources. Moreover, for the same individual, the availability and efficiency of resources undergo fundamental changes throughout life. Adult development is characterized by a shift in directions of lesser resource gains and more resource losses (e.g., Baltes, 1987). Although individuals might gain, for example, in social status, material belongings, knowledge, and professional expertise, other resources such as physical fitness, health, sensory acuity, multitasking ability, or functional brain efficacy decrease throughout adulthood.

The decreasing gain-loss ratio of resources across the adult life span does not inevitably compromise adaptive functioning. This is perhaps best illustrated by the finding of an age-related increase of heterogeneity in functional status, with a good proportion of individuals aging successfully by various subjective and objective criteria, at biological, cognitive, and social levels. Hence, an intriguing task, also at the heart of research on successful aging (for an overview, see Freund \& Riediger, 2003), is to better understand how individuals manage to reach and maintain desirable levels of functioning in a life phase that is characterized by a wealth of objective and subjective resource losses.

In line with Navon (1984), we regard it as helpful to distinguish two classes of resources: commodities and alterants (Freund \& Riediger, 2001; Li \& Freund, 2005). The central characteristic of commodities is their finitude. Many important resources, such as time, 
physical energy, and neurocognitive capacity, are only available in limited amounts. In contrast, alterants, are not finite in themselves but influence the efficiency of using finite commodities. In the context of cognitive aging research, for instance, processing speed, working memory, and attention as well as their neural correlates are assumed, with varying degrees of explanatory power depending on theoretical preferences, as finite, depleting resources. Lifelong experiences in specific domains (expertise) and various forms of contextual support (e.g., from social networks to technologically engineered environmental support for older people), however, can be considered as alterants that improve the efficiency of applying depleting cognitive resources.

Various current conceptual frameworks in life span development emphasize the interaction between life span changes in the availability of limited resources (commodities) and ways in which individuals utilize these resources for successful development (alterants). Next, we briefly discuss the central propositions of four such current frameworks: socioemotional selectivity theory (Carstensen, Isaacowitz, \& Charles, 19991; dual-process model of assimilative and accommodative coping (Brandtstädter \& Renner. 1990', optimization in primary and secondary control (Heckhausen \& Schulz, 14y5), and selection, optimization, and compensation (Baltes \& Baltes, 1990). We then focus specifically on the latter framework and demonstrate its utility for integrating findings on diverse developmental phenomena and for conceptualizing new lines of research.

\section{Four Current Approaches to Adaptive Regulation of Life Span Development}

This section introduces four current approaches to adaptive regulation of life span development. All four frameworks converge on the assumption that the adaptive regulation of life span development requires suitable mechanisms for the allocation of limited resources. They vary, however, in their particular focus (e.g., on social motivation, coping, or control), in the particular characteristics of the proposed resource-allocation mechanisms, and in their postulated generality.

\section{A. Socioemotional Selectivity Theory}

Focusing on social relationships, Carstensen and colleagues postulated socioemotional selectivity as a mechanism regulating age-associated changes in future time perspective (e.g., Carstensen, 1993, 1998; Carstensen et al., 1999). The authors propose two primary motivations for social interaction, emotion regulation and knowledge acquisition. Perceived future time perspective is assumed to determine the relative importance of these motivational objectives. An extended future time perspective tends to be related to knowledge-related goals. A limited future time perspective, in contrast, tends to be related to emotion-related goals.

The authors further postulate that knowledge- and emotion-related goals are more likely to be achieved by interactions with different social partners. Emotion regulation is enhanced with familiar and close interaction partners. Knowledge acquisition, in contrast, often requires interacting with people who are emotionally not very close, but who can give access to desired information. Based on these considerations, the authors argue that the well-documented reduction in social contacts in later adulthood largely results from a selective pruning process that older adults intentionally initiate in accordance with their socialinteractional priorities. Because of their limited future time extension, older 
adults are assumed to be more motivated to regulate emotions than to acquire knowledge. Older adults are therefore predicted to discard emotionally less important relationships in order to selectively invest time and effort into the maintenance of intensive relations to emotionally close interaction partners.

The basic predictions of socioemotional selectivity theory have received empirical support in a variety of studies (for an overview, see Carstensen, Fung, \& Charles, 2003). Empirical evidence also indicates that socioemotional selectivity is not exclusive to old age. Rather, and in line with the theory, it appears to operate whenever future time perspective is perceived as limited, such as in the case of severe illness (e.g., Fredrickson \& Carstensen, 1990; Fung, Carstensen, \& Lutz, 1999).

\section{B. Dual-Process Model of Assimilative and Accommodative Coping}

Whereas the socioemotional selectivity theory focuses on social-motivational phenomena, the dual-process model proposed by Brandtstädter and colleagues (e.g., Brandtstädter \& Greve, 1994; Brandtstädter \& Renner, 1990) addresses coping strategies for maintaining a sense of continuity and efficacy in the face of resource losses. According to this framework, people use two complementary forms of coping to reestablish congruence between desired and actual states when faced with difficulties. Assimilation (e.g., tenacious goal pursuit) involves active and intentional efforts to change life circumstances such that the discrepancy between actual and desired states reduces or disappears. Accommodation (e.g., flexible goal adjustment), in contrast, denotes discrepancy reduction through the automatic (i.e., unintentional) adjustment of preferences and goals to situational constraints.

The authors posit that people usually first employ assimilative coping efforts to actively overcome obstacles that block their goals. If these attempts turn out unsuccessful, a gradual shift to accommodative processes of automatic goal adjustment is postulated, which is modulated by personal and situational factors (e.g., goal importance, success probability, Brandtstädter \& Wentura, 1995).

Empirical evidence demonstrates a general shift from assimilative to accommodative coping and an increasing adaptiveness of the latter in later adulthood when losses become more widespread and resources necessary for tenacious goal pursuit in the face of obstacles decline (Brandtstädter \& Renner, 1990; Brandtstädter, Rothermund, \& Schmitz, 1997; Brandtstädter, Wentura, \& Greve, 1993).

\section{Optimization in Primary and Secondary Control}

The model of optimization in primary and secondary control proposed by Heckhausen and Schulz (1995) assumes that humans have a basic need for control. The primary way to achieve control is by modifying the environment according to one's goals. If such primary control efforts are not available or fail, a secondary way to achieve control (i.e., to protect oneself in the face of difficulties and setbacks) is to modify one's goals and standards or to engage in self-protective attributions and social comparisons. At first glance, this bipartite partioning of control needs resembles the dual-process model proffered by Brandtstädter and colleagues. However, whereas Heckhausen and Schulz (1995) posit a developmental ordering of control mechanisms as primary and secondary, the dual-process model does not assign 
a developmental or conceptual priority to assimilation or accommodation but emphasizes their interplay through all phases of life (e.g., Brandtstädter \& Rothermund, 2002; cf. Piaget, 1980).

Heckhausen and Schulz (1995) further proposed that selectivity and failure compensation are two basic requirements for adaptive developmental regulation. Integrating these two basic requirements of human functioning and the two fundamental types of control, these authors postulated four developmental regulatory mechanisms. Selective primary control denotes the focused investment of resources (e.g., time, effort) into the pursuit of a chosen goal. Compensatory primary control involves the recruitment of external help or technical aids for the attainment of a chosen goal. Selective secondary control subsumes metavolitional strategies to keep oneself focused on the pursuit of selected goals, e.g., by avoiding distractions. Finally, compensatory secondary control serves to buffer negative effects of failure experiences. It involves, for instance, such strategies as disengagement from unattainable goals, downward social comparisons, or external causal attributions.

According to the authors, none of these four strategies is functional per se. Rather, a higher order optimization process is postulated that coordinates control strivings such that the potential for primary control is maximized across the life span. Consistent with this proposition is empirical evidence indicating that self-protective compensatory strategies (compensatory secondary control) become more prevalent and more adaptive in later adulthood and when opportunity structures for goal attainment are unfavorable (Wrosch \& Heckhausen, 1999), whereas continued involvement in primary control efforts may be maladaptive in such situations /Chipperfield, Perry, \& Menec,
1999; Heckhausen, Wrosch, \& Fleeson, 2001).

\section{The Meta-Model of Selection, Optimization, and Compensation}

From the outset (e.g., Baltes \& Baltes, 1990|, the model of selection, optimization, and Compensation was proposed as a general framework of adaptive development that is apt to represent the dynamics between developmental gains and losses across various periods of the life span (e.g., childhood, adolescence, adulthood, old age), at different levels of analyses (e.g., neuronal, behavioral, societal), and within and across domains of functioning (e.g., cognitive development, affect regulation).

Within the SOC framework, adaptive development is defined as a tendency toward simultaneous minimization of losses that impair effective functioning and maximization of gains that promote growth and maintenance. It proposes that adaptive development results from the interaction of three general mechanisms for generating, releasing, and allocating resources: selection, optimization, and compensation. As a meta-theory, the SOC framework does not designate any specific content to these mechanisms, which are proposed to have a multitude of possible phenotypic realizations that may vary along dimensions, such as active-passive, internal-external, and intentional-unintentional. Specific implementations depend on the situation, the relevant domain of functioning, the sociocultural context, individual resources, and personal preferences (Baltes, 1997).

Because pursuing all potentially possible developmental pathways typically exceeds available resources, SOC theory posits that selection from the pool of available alternatives is one of the main mechanisms of developmental 
regulation (Waddington, 1975). The model distinguishes two forms of selection that serve different regulatory functions in life span development: Elective selection occurs in response to new demands or tasks, whereas loss-based selection occurs as a consequence of actual or anticipated loss of resources. Focused investment of resources gives development its direction and is a precondition for developmental specialization and the achievement of higher levels of functioning. Optimization reflects the gain aspect of development, defined as the acquisition, refinement, and coordinated application of resources directed at the achievement of higher functional levels. Finally, compensation addresses the regulation of loss in development. It involves efforts to maintain a given level of functioning despite decline in, or loss of, previously available resources. It thus represents an alternative to loss-based selection, which implies a reorganization of life and functioning around the loss.

\section{The Utility of SOC as an Integrative Framework: Selective Review of Empirical Findings}

So far, we have introduced four different conceptual frameworks that seek to identify developmental processes that regulate the allocation of limited resources to various life domains and life tasks. Next, we review empirical evidence of resource allocation in adulthood and old age, drawing primarily, but not exclusively, on research motivated by the SOC framework. This section focuses on two research domains in which research on SOC mechanisms has been most active: motivational-volitional processes and sensorimotor-cognitive functioning.
A. Motivation and Volition: Mechanisms of Active Life Management

To date, the SOC framework has been most influential in stimulating research on active life management (cf. Freund \& Baltes, 2000) or intentional selfdevelopment (cf. Brandtstädter, 1999). Both notions emphasize the assumption that individuals themselves actively influence the course of their lives through goal-directed action.

Freund and Baltes (2000) elaborated that, in the domain of active life management, SOC mechanisms become evident in motivational and volitional processes. For instance, the selection mechanism unfolds in the process of goal selection. Goals are "desired states that people seek to obtain, maintain, or avoid" (Emmons, 1996, p. 314). Elective selection here denotes committing oneself to goals directed at the achievement of higher levels of functioning. In contrast, lossbased selection, involves changing goals or the goal system in response to losses in previously available goal-relevant resources. It is proposed to represent an adaptive strategy for focusing or redirecting resources when compensatory efforts (see later) to maintain one's goal(s) in the face of resource loss are either not possible or would be invested at the expense of other, more promising goals. In contrast, optimization and compensation are reflected in behaviors involved in goal pursuit. The distinguishing characteristic is the absence or presence of loss in previously available goal-relevant resources. Compensation, in contrast to optimization, aims at counteracting or avoiding losses rather than achieving higher levels of functioning.

Freund and Baltes (2002a) used proverbs to assess people's intuitive knowledge about the effectiveness of these life-management strategies. Proverbs contain historically accumulated cultural 
experience and provide guidelines of how one should act in certain situations or contexts. The authors identified a large range of proverbs that reflect instantiations of selection (e.g., "Those who follow every path never reach any destination."), optimization (e.g., "Practice makes perfect."l, and compensation (e.g., "When there's no wind, grab the oars."). In a series of studies, the authors then paired these proverbs with proverbs representing alternative, non-SOCrelevant life management strategies (e.g., "Good things come to those who wait"). Proverbs in each pair were matched with regard to familiarity, comprehensibility, and perceived meaningfulness. Younger and older participants typically chose SOC-related proverbs as giving better general advice and as matching general life decision situations better than proverbs representing alternative life management strategies. However, when the task was to decide which proverb matches better in situations that focus on relaxation, such as during a vacation, participants typically preferred the alternative to the SOC-related proverbs. The authors concluded that cultural as well as individual knowledge about the pragmatics of life includes representations of selection, optimization, and compensation and that this knowledge is well elaborated and context specific.

Other research indicates that people not only know about but also engage in SOC strategies and that this is associated positively with indicators of adaptive development in various life domains. Such research has employed different measures of SOC. The so far most frequently used instrument is a selfreport questionnaire (SOC questionnaire, Baltes et al., 1999; Freund \& Baltes, 2002b). Other indicators have been derived, for example, from minuteto-minute reconstructions of the sequence, duration, geographical, and social context of everyday activities
(Baltes \& Lang, 1997; Lang, Rieckmann, \& Baltes, 2002), from content analyses of strategies employed to cope with disability (Bouchard Ryan et al., 2003; Gignac, Cott, \& Badley, 2000, 2002), or from patterns of self-reported resource investment in various domains of life (e.g., Staudinger \& Freund, 1998; Staudinger et al., 1999; Wiese, 2000; Wiese \& Freund, 2000).

These measures of engagement in SOC strategies have been linked to various general and domain-specific indicators of adaptive development. General criteria involved, for example, facets of positive psychological functioning, emotional well-being, or life/aging satisfaction (e.g., Chou \& Chi, 2002; Freund \& Baltes, 1998, 2002b; Jopp, 2002; Staudinger \& Freund, 1998; Staudinger et al., 1999|. Domain-specific indicators have so far been obtained primarily in the partnership/family and work/study domains. Examples are partnership and job satisfaction (e.g., Wiese, Freund, \& Baltes, 2000, 2002), workplace performance (Abraham \& Hansson, 1995; Bajor \& Baltes, 20031, experience of work-related stressors, family-related stressors, and workfamily conflict (Baltes \& Heydens-Gahir, 20031 , or learning quantity and learning quality in university students (Wiese \& Schmitz, 2002). Without exception, these studies demonstrated that higher engagement in SOC-relevant life management strategies is predictive of concurrent as well as future developmental success (for examples of prospective study designs, see Jopp, 2002; Wiese et al., 2002). This predictive value of SOC has been shown in samples of healthy adults in different age groups, namely younger adults (e.g., Wiese, 2000; Wiese \& Freund, 2000; Wiese et al., 2000, 2002; Wiese \& Schmitz, 2002), middle-aged adults (e.g., Bajor \& Baltes, 2003), old and very old adults (e.g., Chou \& Chi, 2002; Freund \& Baltes, 1998|, and in a sample covering the adult life span (Freund 
\& Baltes, 2002b). In all, these findings of positive (rather than negative or no) associations between SOC-relevant strategies and indicators of adaptive development are consistent with the proposition that engagement in SOC-relevant strategies fosters adaptive regulation of life span development.

In the Freund and Baltes (2002b) study, adults of various age groups differed in their self-reported engagement in SOC lassessed with the SOC questionnaire; Baltes et al., 1999). Middle-aged adults reported stronger engagement than younger and older adults in loss-based selection, optimization, and compensation. Elective selection showed a linear increase from younger, to middle-aged, and older adulthood. Using a qualitative approach to the assessment of SOC, Gignac et al. (2002) observed a similar pattern in a sample of older patients. These authors content-coded patients' descriptions of behavioral adaptations to osteoarthritis along dimensions of selection (not distinguishing between elective and loss-based selection), optimization, and compensation. In this sample (patients older than 55 years), engagement in all three SOC strategies was slightly negatively associated with age.

Freund and Baltes (2002b) offered the following interpretation of these crosssectional age gradients. In younger adulthood, individuals may still need to explore different developmental pathways to find their way in life, and also have the necessary resources for such explorations (e.g., time to live, energy). As individuals move into middle adulthood, they acquire and refine resourceefficient life management strategies (SOC). Engagement in SOC, however, is itself resource intensive. In older adulthood, therefore, engagement in SOC strategies may again decrease because their implementation is more effortful than alternative behaviors and actions, such as immediately giving up goals in the face of difficulties without attempting to compensate or to select alternative goals. An aging-associated decline in goal-relevant resources therefore limits the expression of optimizing goal pursuit and counteracting goal-related losses in later adulthood. For the same reason, elective selection may become more pronounced with age because the necessity to focus the remaining resources efficiently on selected goals increases.

In support of the assumption that engagement in SOC strategies is resource intensive, studies have shown that resource-rich individuals tend to exhibit higher levels of engagement in SOC strategies than resource-poor individuals (Baltes \& Lang, 1997; Jopp, 2002; Lang et al., 2002). Furthermore, there is accumulating evidence that engagement in SOC-related life management strategies is particularly effective when resources are limited (Abraham \& Hansson, 1995; Chou \& Chi, 2002; Jopp, 2002; Staudinger \& Freund, 1998; Staudinger et al., 1999). In such situations, engagement in SOC strategies has been shown to buffer the negative effect of scarce resources on indicators of adaptive development. Chou and Chi (2002), for example, showed that engagement in selection and optimization, as assessed with the SOC questionnaire, moderated the negative association between financial strain and life satisfaction among elderly Chinese. Elderly participants experiencing high financial strain reported less impaired life satisfaction when they were highly engaged in these strategies and more impaired life satisfaction when they were not.

In summary, in the domain of active life management, SOC-related processes become evident in the selection of personal goals, optimization of goal pursuit, and compensation of goal-relevant resource losses. Empirical evidence demonstrates that people have intuitive 
knowledge about the effectiveness of these life management strategies and that engagement in these strategies is related positively to a diversity of indicators of developmental success, particularly so in increasingly resourceconstraining life conditions, such as older adulthood.

We propose that future research on motivational and volitional aspects of developmental regulation would benefit from using the SOC framework to identify specific aspects of goal selection and goal pursuit behaviors that foster adaptive development in adulthood and old age. Various authors have argued that not all expressions of goal selection and pursuit (SOC) are equally adaptive (Freund \& Baltes, 2000; Freund, Li, \& Baltes, 1999; Marsiske et al., 1995). Selecting too early or too few goals, for example, might impair one's flexibility, a characteristic necessary for continued growth and development (Heckhausen, 1999). Similarly, optimization and compensation can take inappropriate forms and have negative consequences (e.g., Bäckman \& Dixon, 1992). Not investing enough resources, investing resources that do not have the desired effect, or overinvesting resources at the expenses of other goals or one's own health and well-being would be examples for SOC-related actions with potentially maladaptive consequences. These examples underscore that SOC mechanisms need to be tuned to the developmental task and orchestrated among each other in order to be adaptive (e.g., equilibrated; cf. Piaget, 1985). For more effective separation of adaptive from less adaptive forms of goal selection and pursuit in a particular developmental situation, person and context characteristics as well as dynamics among SOC mechanisms need to be taken into account (for examples, see Riediger \& Freund, 2004; Riediger, Freund, \& Baltes, 2005). From an applied perspective, such knowledge would provide an empirical foundation for intervention programs aimed at fostering successful development and aging in particular target groups (for similar propositions, see Cerrato \& Fernanández de Trocóniz, 1998; Chou \& Chi, 2002; Vondracek \& Porfeli, 2002).

\section{B. Cognitive and Sensorimotor Dual Tasking: Adaptive Cross-Domain Resource Allocation}

A salient and ecologically valid component of active life management consists in the simultaneous management of cognitive and sensorimotor aspects of behavior. Cognitive and sensorimotor requirements frequently have to be mastered simultaneously, for example, when conducting a conversation while walking. Therefore, life span changes in coordinating simultaneous demands on sensorimotor and cognitive functions provide a fertile ground for exploring SOC mechanisms.

The resource metaphor has a long tradition in cognitive psychology (e.g., Miller, 1956). Defined as a set of functions or structures relevant to perform a task (Heuer, 1996), it captures processing constraints during single and multitasking at a molar level of analysis, i.e., above the level of specific task-relevant processes. A good example is the unitary resource theory proposed by Kahneman (1973). This framework assumes that different tasks require different amounts of a general mental resource (referred to as attention, capacity, or effort), which is limited, although the limit is variable, and divisible between tasks (cf. Kinsbourne \& Hicks, 1978). Thus, cognitive resources considering as a finite commodity that can be allocated in a highly flexible manner and theorizing at the level of cognitive resources allow researchers to make and test predictions 
about life span changes in adaptive resource allocation. ${ }^{1}$

Research on cognitive-sensorimotor couplings in adulthood has provided ample evidence for three interrelated assumptions. First, both cognitive and sensorimotor tasks draw upon attentional resources, with much variability among tasks in both domains of functioning (e.g., Woollacott, 2000). Second, the overall capacity of available attentional resources decreases with advancing adult age (e.g., Craik \& Byrd, 1982). Third, due to increasing frailty, sensory impairments, and less reliable sensory coordination processes, older adults need to invest more cognitive resources, in both absolute and relative terms, into the regulation of sensorimotor behavior than younger adults (e.g., Brown \& Woollacott, 1998). This increasing need for a decreasing resource constitutes a quandary of behavioral aging (Lindenberger, Marsiske, \& Baltes, 2000l.

Supportive evidence for these claims is typically based on dual-task experiments, in which participants perform a single cognitive task (e.g., memorize a word list), a single sensorimotor task (e.g., walk a narrow track), and both tasks simultaneously. Dual-task costs are then determined as the relative decrement in performance in dual-task as compared to single-task conditions.

\footnotetext{
${ }^{1}$ Various process accounts of resource restrictions have been proposed. For instance, it has been proposed (a) that some mental process needed for one task must wait as long as the person engages in another task (single-channel hypothesis, e.g., K. J. W. Craik, 1948); (b) that processes of stimulus identification and interpretation are inherently limited, which forces people to work on one task at a time only (perceptual bottleneck hypothesis, e.g., Broadbent, 1958); or (c) that individuals can only select responses for one task at a time (responseselection bottleneck hypothesis, e.g., Pashler, 1984). The purpose of this chapter is not to discriminate among these accounts, but to provide a more general overview of life span dynamics in sensorimotorcognitive couplings from a SOC perspective.
}

Various studies using different cognitive and sensorimotor tasks demonstrated that aging is associated with increasing dual-task costs (for overviews, see Li, Krampe, \& Bondar, in press; Woollacott \& Shumway-Cook, 2002). Li and colleagues (2001) extended the dual-task paradigm by varying task difficulty levels. Younger adults' cognitive dual-task costs were independent of the difficulty of the sensorimotor task. Older adults' cognitive performance, however, was significantly more impaired when simultaneously performing a difficult rather than an easy sensorimotor task. These results are consistent with the view that sensorimotor functioning in older adulthood draws increasingly on attentional resources.

SOC provides a suitable framework for investigating adaptive resource allocation processes in dual-task situations involving cognitive and sensorimotor functioning. The framework suggests that selection (i.e., prioritization of more important situational demands at the cost of less important ones) and compensation (i.e., utilization of compensatory means to counteract losses in prioritized aspects of the situation) should be effective mechanisms to cope with age-related declines in cognitive and sensorimotor capacity. Because declining physical capacity in older adulthood results in a higher vulnerability to falls and, in the case of falling, in aggravated risk of serious injuries with debilitating long-term health outcomes, securing one's sensorimotor functioning (e.g., walking safely, keeping one's balancel should have a higher immediate relevance for adaptive functioning in older than in younger adulthood. Older adults should therefore be inclined to protect their sensorimotor functioning (e.g., to walk safely or keep their balance) even at the cost of cognitive performance. This prediction has received initial, but not unequivocal, empirical support by recent experimental studies. 
Several studies found that older participants tend more to prioritize sensorimotor functioning (e.g., postural control) over cognitive performance than younger adults (e.g., Brown et al., 2002; Lajoie et al., 1996; Teasdale et al., 1992, 1993). For instance, Lövdén et al. (in press) found that older adults profited more than young adults when they were allowed to hold onto a handrail while walking on a treadmill and performing a spatial navigation task. Li et al. (2001) found that younger and older adults did not differ in dual-task costs of walking performance when simultaneously memorizing word lists, but that older adults showed higher dual-task memory costs. Other researchers, e.g., Lindenberger et al. (2000), however, did not observe this pattern, perhaps because the difficulty level of the sensorimotor task was not sufficiently high to induce older adults to protect their bodies at the expense of cognitive performance.

Further findings on the selective use of external aids are of particular interest from a SOC perspective. Li et al. (2001) provided memory and walking aids that participants could use in a self-paced manner in conditions with increased task difficulty. The memory aid delayed the presentation of to-be-remembered words to enhance encoding. The walking aid consisted of a handrail that participants could use to stabilize their balance. Older participants not only preferred but also benefited more from using external aids to optimize their walking performance than younger adults. In contrast, younger adults preferred and benefited more from aid use to optimize their memory performance (for another example of age group differences in compensatory strategies in dual-task situations of a different nature, see Kemper, Herman, \& Lian, 2003).

These findings on age differential resource allocation in cognitive-sensorimotor dual-task settings open up a difficult question: To what extent does the observed prioritization of sensorimotor over intellectual dimensions of behavior among older adults result from the flexible and deliberate use of resource allocation strategies (e.g., SOC at the level of deliberate action), as opposed to an automatic mechanism protecting bodily integrity (e.g., SOC at the level of behavioral regulation)? One way to investigate this question is to employ different task-emphasis instructions in dual-task designs. Although some studies show age-related deficits in deliberate resource allocations (Anderson, Craik, \& Naveh-Benjamin, 1998; Tsang \& Shaner, 1998), the majority of available studies show that older adults are as able as younger adults to deliberately emphasize either one (e.g., motor) or the other (e.g., cognitive) component task when instructed to do so /Crossley \& Hiscock, 1992; Salthouse, Rogan, \& Prill, 1984; Somberg \& Salthouse, 1982). For example, Bondar, Krampe, and Baltes (2005) found that older adults were equally or better able than younger adults to follow instructions of varying task emphasis under dual-task conditions, i.e., to prioritize either sensorimotor or cognitive aspects of performance. The authors concluded that older adults' selective prioritization of sensorimotor aspects in multiple-task situations resulted from their ability to flexibly and deliberately withdraw cognitive resources from a cognitive component in order to secure the more survival-relevant sensorimotor functioning. Such deliberate strategic choices may be operating on top of more automated protection mechanisms.

In summary, research on resource allocation processes in multitask situations involving cognitive and sensorimotor tasks has demonstrated an aging-associated increase in loss-based selection and selective compensation. Older adults tend to prioritize safe 
sensorimotor functioning (e.g., walking, keeping balance) at the cost of simultaneous cognitive demands. To some degree at least, this form of selective optimization appears to result from older adults' maintained ability to flexibly allocate attentional resources. Given the increased susceptibility to, and aggravated consequences of falling, prioritization of sensorimotor functioning can tentatively be classified as an adaptive strategy of older adults. Future research would benefit from further investigation of the adaptive values of resource allocation processes in sensorimotor-cognitive dual task settings. For example, are there interindividual differences among older adults in the ability to flexibly allocate attentional resources to protect sensorimotor functioning? Are older adults who tend to be less selective in this respect more susceptible to falls, as clinical observations would suggest (Sattin, 1992; Tinetti, 1995)? From an applied perspective, responses to these questions might help conceptualizing prevention programs targeting older adults at high risk of falling.

\section{Research on SOC: Future Directions}

Thus far, we have used the SOC framework to organize and integrate evidence on resource allocation processes across age periods, levels of analysis, and content domains. Resource allocation processes in domains as diverse as motivation/volition and cognitive-sensorimotor functioning can be phrased and interpreted in terms of selection, optimization, and compensation mechanisms. In this manner, the SOC framework may contribute to a more coherent and holistic picture of human development and aging. Moreover, the SOC framework also has the potential to inspire new research questions and paradigms. This section illustrates this claim with select research examples, again drawn from the domains of active life management and cognition. Finally, we propose formal modeling to further develop the predictive potential of the SOC framework.

\section{A. Social Embedding of Active Life Management: SOC in Multiple-Person Systems}

There is clear agreement among current developmental psychologists that an individual's development is fundamentally shaped and constrained by his or her environment. It is also generally acknowledged that such contextual forces are manifold, including normative age-graded, normative history-graded, and nonnormative influences (see Baltes, 1987), and that many of these influences involve social aspects and processes. Despite this general acknowledgement of the importance of social contexts (Baltes \& Staudinger, 1996), the majority of studies in developmental psychology, including those reviewed earlier, have taken a person-centered route. We propose that the SOC framework may serve as an organizing framework for surpassing this incongruence between theory and methods. Research on active life management may serve as an example to illustrate this claim.

Active life management refers to the fact that people themselves influence their development within the range of available opportunities. In this regard, SOC mechanisms have been proposed to unfold in the selection of personal goals, optimization of goal pursuit, and compensation of losses in goal-relevant resources (Freund \& Baltes, 2000; Freund et al., 1999). We propose that future research should investigate the social foundations of these processes. We regard two research perspectives as particularly promising. 
From a social-interactive perspective, motivational and volitional processes within individuals can be viewed both as a source and as a target of social influence. This approach can yield important information on other people's influence on the content and pursuit of an individual's goals, on the impact of an individual's goal selection and pursuit on his or her social environment, and especially on the development of such social-interactive components and their associations with successful life management in various phases of the life span, such as older adulthood.

From a social-interactive perspective, the focus is on the individual as embedded in social contexts. From a collective perspective, the focus is on social systems (e.g., dyad, family, work groupl as a whole. According to the SOC framework, selection, optimization, and compensation also operate at this level of analysis (e.g., Baltes \& Carstensen, 1998). In terms of life management, then, social systems can be seen as selecting goals and as striving toward goal attainment (see also von Cranach, Ochsenbein, \& Valach, 1986). This perspective can yield important information on processes fostering successful development of social units, such as partnerships or intergenerational relations.

In our view, SOC is apt to synthesize both perspectives, social interactive and collective, within the same theoretical framework. This has two advantages. First, it allows relating formerly disconnected evidence from the socialinteractive perspective (e.g., finding of a dependence support script that undermines older adults' striving for independence, Baltes, 1996), on the one hand, and the collective perspective (e.g., finding that collective goal setting improves work group performance, Wegge, 2000), on the other. Second, it stimulates empirical research efforts that combine both perspectives. Such research might address, for example, interrelations among individual and collective goal processes, antecedents and consequences of collective goal processes on the individual and collective level, or life span trajectories of competencies involved in individual and collective goal processes.

\section{B. Life Span Development of Selection Mechanisms}

According to the SOC framework, selection is particularly important when processing resources are scarce. Everyday cognitive functioning is a continuous stream of simultaneous and sequential multitasking (e.g., finding one's way through a mall while memorizing a shopping list, watching one's purse, and talking to a friend), thus requiring flexible resource allocation across functions and task domains on the part of the individual. Resource allocation is in turn supported by selection mechanisms that are either primarily more resource based or more process based, as discussed here.

\section{Resource-Based Selection}

Conceptually, scarcity in processing resources refers to cases where total demands required by multiple tasks exceed the total available resources. An example is reading a text while taking care of a small child. Overlap in resources, however, refers to situations where multiple tasks overlap substantially in the resources they require, such as when taking care of several small children. Although resource scarcity and resource overlap may be independent of each other, most daily cognition involves carrying out multiple tasks with overlapping requirements on limited resources, simultaneously, sequentially, or both. 


\section{Process-Based Selection}

Other than resource-based selection, a less noted aspect of selection refers to processing conflict, such as a mismatch between current task requirement and already well-established behavioral or neurocognitive processing patterns. Such processing conflicts between old habits and new task demands occur regularly in everyday life, for example, when there is change in contexts (e.g., a move to a new apartment), in contact persons (e.g., new neighbors), or in properties of daily devices (e.g., a new personal computer). Such changes necessitate selecting between competing processes, which we refer to as process-based selection (see also Miller \& Cohen, 2001). Throughout life, experiential selection generates habits that could either facilitate or hamper goal or process selection in specific life or task contexts. Experiential selection not only operates at the behavioral level to shape the individual's specific behavioral and cognitive characteristics, it also operates at the neuronal level. Both the selective stabilization theory of neuronal epigenesis (Changeux, 1985) and the neuronal group selection theory (Edelman, 1987) postulate that during early brain development selective experiential influences shape the details of structural and functional organization. Similarly, the neural constructivist view stresses that experiences can selectively strengthen the synaptic efficacy of frequently activated neural assemblies to construct cortical circuits for different specialization (e.g., Johnson, 2001; Quartz \& Senjowski, 2000).

In our view, resource- and processbased selection are not independent of each other and should both be emphasized conjointly in future behavioral and cognitive neuroscience research on life span age differences in selection regulation. The following sections propose (a) how life span age differences in resource-based selection can be studied in the context of multitasking paradigms and (b) how life span age differences in process-based selection can be investigated using differential training and context shift paradigms. In both cases, implementing specific aspects of SOC concepts, such as selection mechanisms, leads to empirically testable predictions.

\section{Age Differences in Resource-Based Selection: The Concept of Selection Margins}

Informed by early work of Brim (1992), we propose that the concept of selection margins may help extend our knowledge of the development of adaptive resource allocation processes in multiple-task situations. We define selection margins as the discrepancy between the number of multiple tasks an individual could maximally manage given the available processing resources and the number of tasks he or she actually selects to work on. Selection margins have three central characteristics: their (a) width, (b) direction, and (c) function for adaptive development (see Figure 13.1).

The width of selection margins refers to the extent of the deviation between self-selected and maximally manageable number of simultaneous tasks. We assume that this width is influenced by the accuracy of people's estimates of the number of tasks they can maximally manage, which in turn should be a function of performance variability and the accuracy of performance and error monitoring. During childhood and aging, when cognitive resources and their underlying neurobiological substrates undergo growth and decline respectively (Li et al., 2004), individuals' performance variability has been shown to be larger and their monitoring operations to be less precise than during late adolescence and adulthood when resources are more 


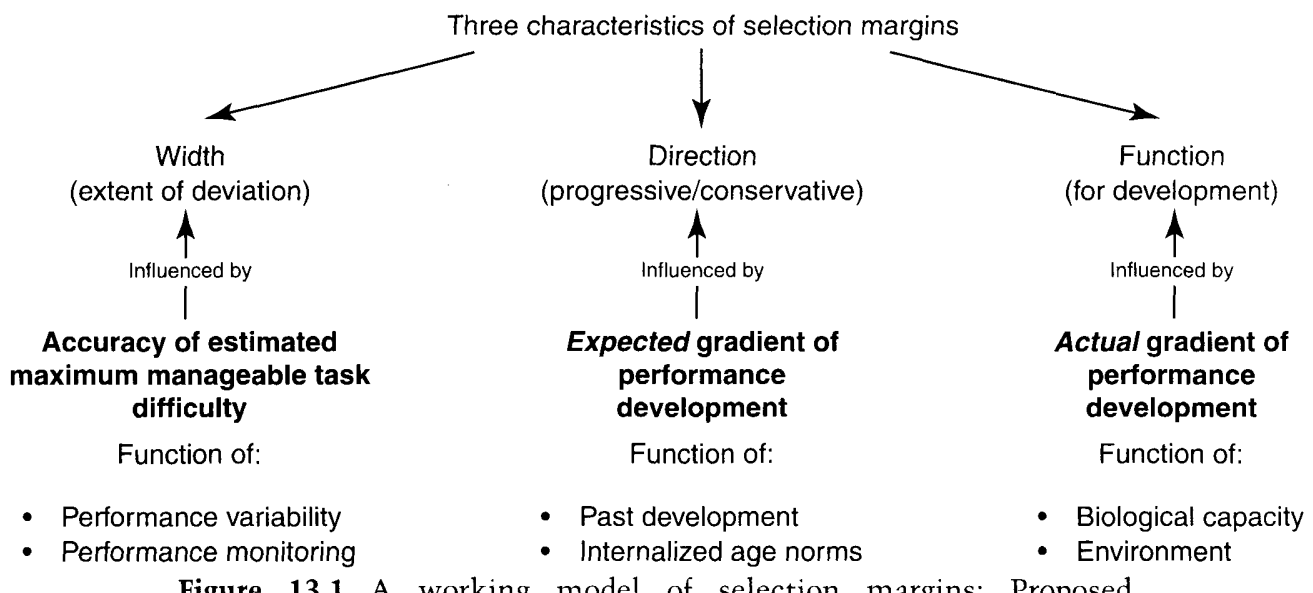

Figure 13.1 A working model of selection margins: Proposed characteristics and antecedents.

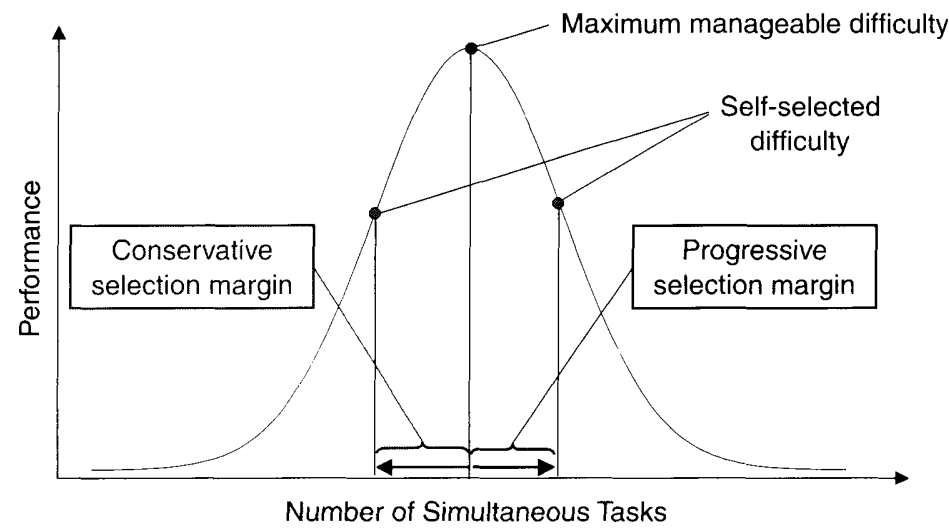

Figure 13.2 The concept of selection margins defined as discrepancy between the number of subtasks an individual could maximally manage given the available processing resources and the number of tasks he or she actually selects to work on.

stable (e.g., Davies, Segalowitz, \& Gavin, 2004; Li et al., 2004; Nieuwenhuis et al., 2002). It can therefore be expected that older adults and children show wider selection margins in cognitive tasks than young adults.

The direction of selection margins is characterized by whether individuals choose task numbers or task difficulties in excess of or below their current ability levels. If an individual chooses to work with a number of subtasks that is smaller than his or her maximum manageable difficulty, the selection margin is conservative. Conversely, if the individual selects to work with a number of subtasks that is greater than his or her maximum manageable difficulty, the selection margin is progressive (see Figure 13.2). We assume that the direction of selection margins is influenced by people's expectations of the future development of their performance. Progressive selection margins should result from expected improvement, and conservative selection margins from expected decline. We further assume that such expectations 
are, to some extent, a function of past experiences of improvement or decline in abilities, and of age-normative expectations. Therefore, older adults may be more likely to adopt conservative selection margins, whereas children are expected to prefer progressive selection margins.

Finally, we assume that the function or adaptivity of selection margins depends on the actual gradient of performance development, which is a function of biological capacity and contextual opportunities and constraints. As a general rule, progressive selection margins may, on average, be more adaptive in childhood, when cognitive abilities are on a growth trajectory and when working on a number of tasks that exceeds the child's current resources should stimulate the full utilization of the developmental potential, thus accelerating the improvement of functioning. Progressive selection margins of moderate width might be most adaptive in this regard. Working on a number of tasks that substantially exceeds the child's current ability level may eventually undermine the taskrelevant motivation.

In turn, whenever progressive selection margins are unlikely to result in accelerated enhancement of behavioral competence, neutral or conservative selection margins may be more adaptive. Therefore, we assume that older adults are more likely to adopt conservative selection margins in functional domains that are characterized by normative age-related decline such as memory and perceptual speed. In SOC terminology, conservative selection margins would function as a mechanism of anticipatory loss-based selection in this case. We assume that conservative selection margins of small width might be most adaptive because they keep individuals safely away from their limits without severely constraining the utilization of the available capacity.

\section{Age Differences in Process-Based \\ Selection: Habituation and Context-Shifting Paradigms}

Adult age differences in maintenance of and reliance on context information for memory processes have been well established. Memory for context is particularly vulnerable in old age (Spencer \& Raz, 1995). At the same time, older adults are also more dependent on the match between encoding and retrieval contexts (e.g., Braver et al., 2001; Castel \& Craik, 2003). Older adults are also less able to inhibit a potent habitual process or behavior and are more susceptible to interference (e.g., Nieuwenhuis et al., 2002). Generalizing from these findings, experimental paradigms that involve a first phase of habituation training for strengthening a particular selection option and a second phase of context match that systematically varies the degree of match between current task context and the habituated context may be a fruitful approach to study life span age differences in process-based selection. On the one hand, if the current task context is particularly similar to the training context, habituation should facilitate the required selection in the current task. On the other hand, if the requirement of the current task context is quite different from the already established habit, processing conflict may result and hamper selection (see Figure 13.3). Thus for old adults, a habituated selection mechanism may be particularly detrimental for selecting the appropriate processes when inference between the habitual context and the current task demand is high.

It has been proposed that the anterior cingulate cortex (ACC) plays an important role in monitoring processing conflict. According to one account, activities in ACC send signals of conflict in processing pathways to the prefrontal 


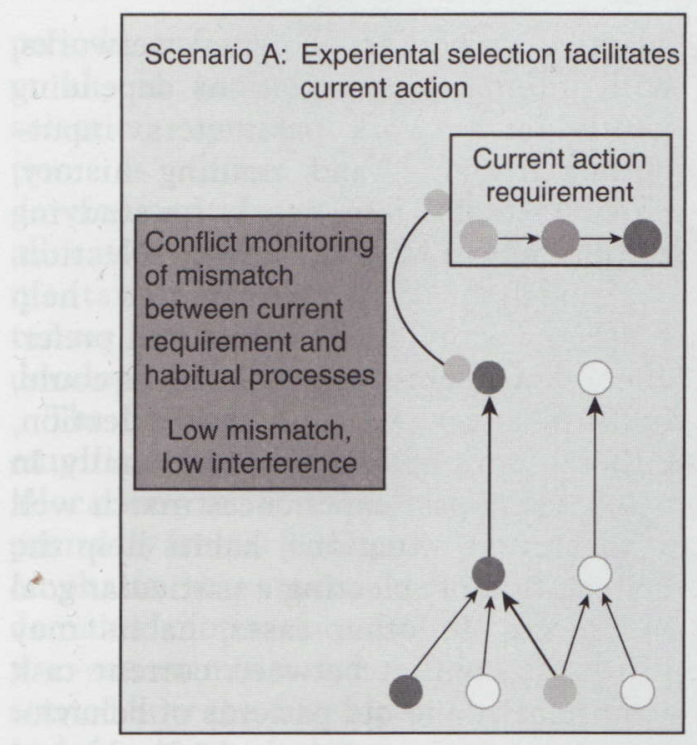

Figure 13.3 Schematic diagram

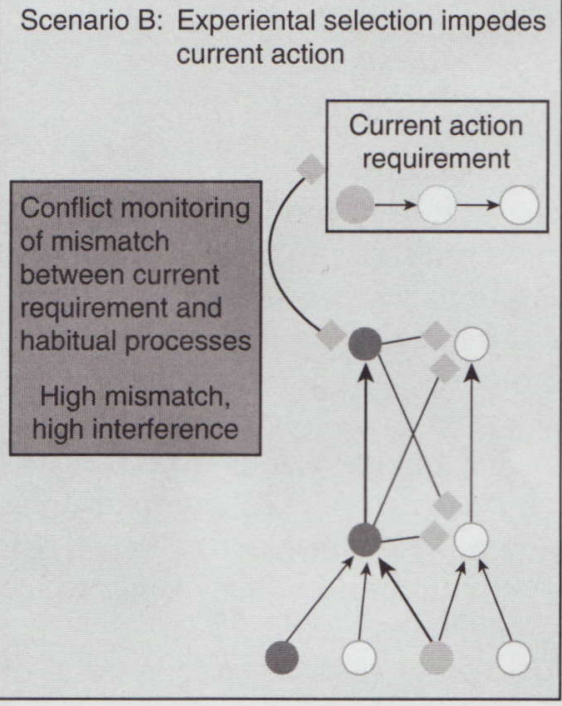

of two scenarios of possible interactions between experiential selection and current actions: Habituated (experientially selected) processes are linked with thick dark lines. When the conflict between current action requirements and experientially selected processes is low, experiential selection facilitates current action (scenario A). In contrast, when conflict between current action requirements and experientially selected processes is high, experiential selection hampers current action (scenario B).

cortex $(\mathrm{PFC})$ in order to generate stronger PFC representations to support (direct) processing in the task-relevant pathways (e.g., Cohen, Aston-Jones, \& Gilzenrat, 2004). Given that aging-related declines implicate both brain regions and the neuromodulatory mechanisms therein (Bäckman \& Farde, 2005; Ohnishi et al., 2001), older adults can be expected to be less efficient at monitoring process conflicts between habituated behavioral patterns and new task demands.

\section{E. Toward Formalization of the SOC Framework}

During the last decade, theoretical implications of the SOC framework have been developed and elaborated with widespread success, but, for the most part, without recourse to formal modeling (e.g., Baltes \& Baltes, 1990; Baltes, 1997; Freund \& Baltes, 2000; Marsiske et al., 1995; see, however, Chow \& Nesselroade, 2004). In our view, formalizing the SOC framework through mathematical or computational models carries the advantage of making the dynamics of SOC mechanisms more explicit and empirically testable. Two specific modeling approaches, nonlinear dynamical systems and neural network models, are used to illustrate this claim. ${ }^{2}$

\footnotetext{
${ }^{2}$ As a third class of models, agent-based approaches may be particularly suitable for formal analyses of age differences in resource-based selection as observed in multitasking situations (Sy-Miin Chow and Paul B. Baltes, personal communication, 2005).
} 
Dynamic Modeling of Age

Differences in Resource

Competition and Task

Prioritization

Dynamic systems models characterize changes according to functional relations and parameters that determine their current state according to previous ones. Developmental psychologists have used dynamic systems notions both as conceptual theories and in various formal mathematical treatments (e.g., connectionist models and catastrophe theories) of developmental changes (for a review, see Smith and Thelen, 2003).

Predator-prey models, a subclass of dynamical models, have been applied successfully to study adult age differences in dual-task resource competition (Chow \& Nesselroade, 2004). In these models, the performance of the two tasks can be specified as a set of two interrelated differential equations to predict learning rates, as well as the intratask and intertask dynamics of adaptive resource allocation. Specifically, age differences in intra- and intertask resource competition can be expressed as differences in the parameters of the differential equation system. We suggest extending these models by including parameters that capture age differences in task prioritization (e.g., emphasizing task domains that have more salient functional significance) in order to formally examine age differences in resource competition as a function of task selection.

\section{Dynamic Neural Network Modeling of Age Differences in Experiential Selection}

A second class of dynamic process models that has been commonly applied in studying developmental changes during childhood is neural networks (for a review, see Munakata \& McClelland, 2003). We suggest that the dynamic adaptive properties of neural networks, with internal representations depending jointly on network parameters, inputoutput mapping, and training history, provide suitable frameworks for studying age differences in process-based selection.

Throughout life, experiences help shape the individual's habits and preferences. Such habits and preferences could, in turn, affect goal and task selection, either intentionally or unintentionally. In cases where past experiences match well with current situations, habits help the deliberation of selecting a particular goal or process. In other cases, habits may introduce conflict between current task requirement and old patterns of behavior or processes (see Figure 13.3). Neural network models have been applied to study the phenomenon of habitual word processing, leading to a color naming disadvantage in the traditional Stroop interference task (Cohen, Dunbar, \& McClelland, 1990|, habituation processes in infant cognition (for a review, see Sirois \& Mareschal, 2004), and aging effects on context processing, susceptibility to inference, and conflict monitoring between targeted performance and error (Braver et al., 2001; Li, Lindenberger, \& Sikström, 2001; Nieuwenhuis et al., 2002). Building on this past work, we propose that neural network simulations are a suitable means for studying interactions between aging-related decline in cognitive resources and process-based selection in situations that require conflict monitoring between current task requirement and well-established habits.

\section{Summary and Outlook}

In our view, the SOC framework, originally developed by Baltes and Baltes (1990), is a valuable meta-theoretical tool for integrating research on life span development across functional domains, life 
periods, and levels of analysis (cf. Baltes et al., in press). Its explicit focus on selection, optimization, and compensation as three key mechanisms of developmental resource generation and allocation effectively counteracts the fragmentation of knowledge that characterizes much of the work in child development and aging.

The first part of this chapter reviewed empirical findings on adaptive resource allocation in adulthood and old age, primarily from a SOC perspective. Special emphasis was given to two research domains: motivation-volition, and cognitive-sensorimotor functioning. We illustrated how the development, expression, and function of diverse developmental phenomena such as goal selection and pursuit and performance in cognitivesensorimotor dual tasks can be regarded as specific implementations of the component processes of selection, optimization, or compensation. We also noted how future research might strengthen the predictive power of the SOC framework.

The second part of this chapter delineated new research directions within the SOC framework. Our choice of suggested research topics was neither exhaustive nor representative. Rather, we opted for a selection of particularly promising and divergent themes to illustrate the range of applicability of the SOC framework. In the social domain, we suggested that future research would benefit from the investigation of age differences in characteristics of resource allocation mechanisms in single- and multiple-person systems. In the motivational domain, we explored how SOC theorizing can be used for deriving research questions that explicitly address the social foundation of active life management. In the cognitive domain, we introduced the concept of selection margins and discussed conflict monitoring between habitual processing and novel task demands. Finally, we arguc: that formal modeling provides a promiing methodological tool for investigating the dynamics of adaptive resource allocation processes in life span development and for formalizing the dynamic properties of SOC theory.

This present chapter focused on the suitability of the SOC framework for understanding regulatory processes of adaptive resources allocation. Such processes play a central role in all functional domains and at all levels of analysis (e.g., interpersonal, behavioral, neuronal), especially when resource limitations become more pronounced, as is the case in old age. We reiterate, however, that the scope of the SOC framework extends beyond resource allocation to resource generation, i.e., it also speaks to the ontogeny of behavioral repertoires and action propensities. In our view, future research would profit from increased attention to the resource generation facet of SOC theory. Such increased attention would also result in a broader appreciation of the optimization mechanism, which presumably plays a key role in resource generation.

\section{Acknowledgement}

We thank Paul B. Baltes and Alexandra $M$. Freund for many insightful comments and stimulating discussions on SOC theory.

\section{References}

Abraham, J. D., \& Hansson, R. O. (1995). Successful aging at work: An applied study of selection, optimization, and compensation through impression management. Journal of Gerontology: Psychological Sciences, 50B, P94-P103.

Anderson, N. D., Craik, F. I. M., \& NavehBenjamin, M. (1998). The attentional demands of encoding and retrieval in younger and older adults. 1. Evidence from 
divided attention costs. Psychology and Aging, 13, 405-423.

Bäckman, L., \& Dixon, R. A. (1992). Psychological compensation: A theoretical framework. Psychological Bulletin, 112, 259-283.

Bäckman, L., \& Farde, L. (2005). The role of dopamine systems in cognitive aging. In R. Cabeza, L. Nyberg, \& D. Park (Eds.), Cognitive neuroscience of aging (pp. 58-84). New York: Oxford University Press.

Bajor, J. K., \& Baltes, B. B. (2003). The relationship between selection optimization with compensation, conscientiousness, motivation, and performance. Journal of Vocational Behaviour, 63, 347-367.

Baltes, B. B., \& Heydens-Gahir, H. A. (2003). Reduction of work-family conflict through the use of selection, optimization, and compensation behaviors. Journal of Applied Psychology, 88, 1005-1018.

Baltes, M. M. (1996). The many faces of dependency in old age. New York: Cambridge University Press.

Baltes, M. M., \& Carstensen, L. L. (1998). Social psychological theories and their applications to aging: From individual to collective. In V. L. Bengtson \& K. W. Schaie (Eds.), Handbook of theories of aging (pp. 209-226). New York: Springer.

Baltes, M. M., \& Lang, F. R. (1997). Everyday functioning and successful aging: The impact of resources. Psychology and aging, 12, 433-443.

Baltes, P. B. (1987). Theoretical propositions of life-span developmental psychology: On the dynamics between growth and decline. Developmental Psychology, 23, 611-626.

Baltes, P. B. (1997). On the incomplete architecture of human ontogeny: Selection, optimization, and compensation as foundation of developmental theory. American Psychologist, 52, 366-380.

Baltes, P. B., \& Baltes, M. M. (1990). Psychological perspectives on successful aging: The model of selective optimization with compensation. In P. B. Baltes \& M. M. Baltes (Eds.), Successful aging: Perspectives from the behavioral sciences (pp. 1-34). New York: Cambridge University Press.

Baltes, P. B., Baltes, M. M., Freund, A. M., \& Lang, F. R. (1999). The measurement of selection, optimization, and compensation (SOC) by self-report: Technical report 1999.
Berlin: Max Planck Institute for Human Development.

Baltes, P. B., Lindenberger, U., \& Staudinger, U. M. (in press). Life span theory in developmental psychology. In W. Damon (Series Ed.) \& R. M. Lerner (Vol. Ed.), Handbook of child psychology (6th edition, vol.1). New York: Wiley.

Baltes, P. B., \& Staudinger, U. M. (1996). Interactive minds in a life-span perspective: Prologue. In P. B. Baltes \& U. M. Staudinger (Eds.), Interactive minds (pp. 1-32). New York: Cambridge University Press.

Bondar, A., Krampe, R. T., \& Baltes, P. B. (2005). The dynamics between balance and cognition in young and old adults: Older adults maintain adaptive flexibility of resource allocation despite higher dualtask costs. Unpublished manuscript.

Bouchard Ryan, E., Anas, A. P., Beamer, M., \& Bajorek, S. (2003). Coping with age-related vision loss in everyday reading activities. Educational Gerontology, 29, 37-54.

Brandtstädter, J. (1999). The self in action and development. Cultural, biosocial, and ontogenetic bases of intentional selfdevelopment. In J. Brandtstädter \& R. M. Lerner (Eds.), Action and selfdevelopment: Theory and research through the life span (pp. 37-65). Thousand Oaks, CA: Sage.

Brandtstädter, J., \& Greve, W. (1994). The aging self: Stabilizing and protective processes. Developmental Review, 14, 52-80.

Brandtstädter, J., \& Renner, G. (1990). Tenacious goal pursuit and flexible goal adjustment: Explication and age-related analysis of assimilative and accommodative strategies of coping. Psychology and Aging, 5, 58-67.

Brandtstädter, J., Rothermund, K., \& Schmitz, U. (1997). Coping resources in later life. European Review of Applied Psychology, 47, 107-114.

Brandtstädter, J., \& Rothermund, K. (2002). The life-course dynamics of goal pursuit and goal adjustment: A two-process framework. Developmental Review, 22, 117-150.

Brandtstädter, J., \& Wentura, D. (1995). Adjustment to shifting possibility frontiers in later life: Complementary adaptive modes. In R. A. Dixon \& L. Bäckman 
(Eds.), Compensating for psychological deficits and declines: Managing losses and promoting gains (pp. 83-106). Hilldale, NJ: Erlbaum.

Brandtstädter, J., Wentura, D., \& Greve, W. (1993). Adaptive resources of the aging self: Outlines of an emergent perspective. Journal of Behavioral Development, 16, 323-349.

Braver, T. S., et al. (2001). Context processing in older adults: Evidence for a theory relating cognitive control to neurobiology in healthy aging. Journal of Experimental Psychology: General, 130, 746-763.

Brim, G. (1992). Ambition: How we manage success and failure throughout our lives. New York: Basic Books.

Broadbent, D. E. (1958). Perception and communication. New York: Pergamon Press.

Brown, L. A., Sleik, R. J., Polych, M. A., \& Gage, W. H. (2002). Is the prioritization of postural control altered in conditions of postural threat in younger and older adults? Journal of Gerontology: Medical Sciences, 57A, M785-M792.

Brown, L. A., \& Woollacott, M. H. (1998). The effects of aging on the control of posture and locomotion in healthy older adults: An emphasis on cognition. Psychologische Beiträge, 40, 27-43.

Carstensen, L. L. (1993). Motivation for social contact across the life span: A theory of socioemotional selectivity. In J. E. Jacobs (Ed.), Nebraska Symposium on Motivation, 1992: Developmental perspectives on motivation. Current theory and research in motivation (Vol. 40, pp. 209-254). Lincoln, NE: University of Nebraska Press.

Carstensen, L. L. (1998). A life-span approach to social motivation. In J. Heckhausen (Ed.), Motivation and self-regulation across the life span (pp. 341-363). New York: Cambridge University Press.

Carstensen, L. L., Fung, H. H., \& Charles, S. T. (2003). Socioemotional selectivity theory and the regulation of emotion in the second half of life. Motivation and Emotion, 27, 103-123.

Carstensen, L. L., Isaacowitz, D. M., \& Charles, S. T. (1999). Taking time seriously: A theory of socioemotional selectivity. American Psychologist, 54, 165-181.
Castel, A. D., \& F. I. M. Craik (2003). The effects of aging and divided attention on memory for item and associative information. Psychology \& Aging, 18, 873-885.

Cerrato, I. M., \& Fernanández de Trocóniz, M. I. (1998). Successful aging. But, why don't the elderly get more depressed? Psychology in Spain, 2, 27-42.

Changeux, J.-P. (1985). Neuronal man. New York: Oxford University Press.

Chipperfield, J. G., Perry, R. P., \& Menec, V. H. (1999). Primary and secondary controlenhancing strategies: Implications for health in later life. Journal of Aging and Health, 11, 517-539.

Chou, K.-L., \& Chi, I. (2002). Financial strain and life satisfaction in Hong Kong elderly Chinese: Moderating effect of life management strategies including selection, optimization, and compensation. Aging and Mental Health, 6, 172-177.

Chow, S. M., \& Nesselroade, J. R. (2004). General slowing or decreased inhibition? Mathematical models of age differences in cognitive functioning. Journals of Gerontology Series B: Psychological Sciences, 59, P101-P109.

Cohen, J. D., Aston-Jones, G., \& Gilzenrat, M. S. (2004). A system level theory of attention and cognitive control. In M. I. Posner (Eds.) Cognitive neuroscience of attention, (pp. 71-90). New York: Guilford Press.

Cohen, J. D., Dunbar, K., \& McClelland, J. L. (1990). On the control of automatic processes: A parallel distributed-processing account of the Stroop effect. Psychological Review, 97, 332-361.

Craik, F. I. M., \& Byrd, M. (1982). Aging and cognitive deficits: The role of attentional resources. In F. I. M. Craik \& S. Trehub (Eds.), Aging and cognitive processes (pp. 191-211). New York: Plenum.

Craik, K. J. W. (1948). Theory of the human operator in control systems. II. Man as an element in a control system. British Journal of Psychology, 38, 142-148.

Crossley, M., \& Hiscock, M. (1992). Agerelated differences in concurrent-task performance in normal adults: Evidence for a decline in processing resources. Psychology and Aging, 7, 499-506. 
Davies, P. L., Segalowitz, S. J., \& Gavin, W. J. (2004). Development of response-monitoring ERPs in 7-to-25 year-olds. Developmental Neuropsychology, 25, 355-376.

Edelman, G. M. (1987). Neural Darwinism: The theory of neuronal group selection. New York: Basic Books.

Emmons, R. A. (1996). Striving and feeling: Personal goals and subjective well-being. In P. M. Gollwitzer \& J. A. Bargh (Eds.), The psychology of action: Linking cognition and motivation to behavior (pp. 313-337). New York: Guilford Press.

Fredrickson, B. L., \& Carstensen, L. L. (1990). Choosing social partners: How old age and anticipated endings make people more selective. Psychology and Aging, 5, 335-347.

Freund, A. M., \& Baltes, P. B. (1998). Selection, optimization, and compensation as strategies of life management: Correlations with subjective indicators of successful aging. Psychology and Aging, 13, 531-543.

Freund, A. M., \& Baltes, P. B. (2000). The orchestration of selection, optimization and compensation: An action-theoretical conceptualization of a theory of developmental regulation. In W. J. Perrig \& A. Grob (Eds.), Control of human behavior, mental processes, and consciousness: Essays in honor of the 60th birthday of August Flammer (pp. 35-58). Mahwah, NJ: Lawrence Erlbaum.

Freund, A. M., \& Baltes, P. B. (2002a). The adaptiveness of selection, optimization, and compensation as strategies of life management: Evidence from a preference study on proverbs. Journal of Gerontology: Psychological Sciences, 57B, P426-P434.

Freund, A. M., \& Baltes, P. B. (2002b). Lifemanagement strategies of selection, optimization, and compensation: Measurement by self-report and construct validity. Journal of Personality and Social Psychology, 82, 642-662.

Freund, A. M., Li, K. Z. H., \& Baltes, P. B. (1999). Successful development and aging: The role of selection, optimization, and compensation. In J. Brandtstädter \& R. M. Lerner (Eds.), Action and self-development: Theory and research through the life span (pp. 401-434). Thousand Oaks, CA: Sage.
Freund, A. M., \& Riediger, M. (2001). What I have and what I do: The role of resource loss and gain throughout life. Applied Psychology: An International Review, 50, 370-380.

Freund, A. M., \& Riediger, M. (2003). Successful aging. In R. M. Lerner, M. A. Easterbrooks \& J. Mistry (Eds.), Handbook of psychology: (vol. 6, pp. 601-628). New York: Wiley.

Fung, H. H., Carstensen, L. L., \& Lutz, A. M. (1999). Influence of time on social preference: Implications for life-span development. Psychology and Aging, 14, 595-604.

Gignac, M. A. M., Cott, C., \& Badley, E. M. (2000). Adaptation to chronic illness and disability and its relationship to perceptions of independence and dependence. Journal of Gerontology: Psychological Sciences, 55B, P362-P372.

Gignac, M. A. M., Cott, C., \& Badley, E. M. (2002). Adaptation to disability: Applying selective optimization with compensation to behaviors of older adults with osteoarthritis. Psychology and Aging, 17, 520-524.

Heckhausen, I. (1999). Developmental regulation in adulthood: Age-normative and sociostructural constraints as adaptive challenges. New York: Cambridge University Press.

Heckhausen, J., \& Schulz, R. (1995). A lifespan theory of control. Psychological Review, 102, 284-304.

Heckhausen, J., Wrosch, C., \& Fleeson, W. (2001). Developmental regulation before and after a developmental deadline: The sample case of "biological clock" for childbearing. Psychology and Aging, 16, 400-413.

Heuer, H. (1996). Dual-task performance. In O. Neumann \& A. F. Sanders (Eds.), Handbook of perception and action (Vol. 3, pp. 113-153). London: Academic Press.

Hobfoll, S. E. (1998). Stress, culture, and community: The psychology and philosophy of stress. New York: Plenum Press.

Johnson, M. H. (2001). Functional brain development in humans. Nature Review Neuroscience, 2, 475-483.

Jopp, D. (2002). Successful aging: On the functional interplay between personal resources and adaptive strategies of life management. Doctoral dissertation, Free 
University Berlin. Retrieved October 10, 2004, from http:/www.diss.fu-berlin.de/ 2003/50/

Kahneman, D. (1973). Attention and effort. Englewood Cliffs, NJ: Prentice-Hall.

Kemper, S., Herman, R. E., \& Lian, C. H. T. (2003). The costs of doing two things at once for younger and older adults: Talking while walking, finger tapping, and ignoring speech or noise. Psychology and Aging, 18, 181-192.

Kinsbourne, M., \& Hicks, R. E. (1978). Functional cerebral space: A model for overflow, transfer and interference effects in human performance: A tutorial review. In I. Requin (Ed.), Attention and performance VII (pp. 345-362). Hillsdale, NJ: Lawrence Erlbaum.

Krampe, R. T., \& Baltes, P. B. (2003). Intelligence as adaptive resource development and resource allocation: A new look through the lenses of SOC and expertise. In R. J. Sternberg \& E. L. Grigorenko (Eds.), Perspectives on the psychology of abilities, competencies, and expertise (pp. 31-69). New York: Cambridge University Press.

Lajoie, Y., Teasdale, N., Bard, C., \& Fleury, M. (1996). Attentional demands for walking: Age-related changes. In A.-M. Ferrandez \& N. Teasdale (Eds.), Changes in sensory motor behavior in aging (pp. 235-256). Amsterdam: Elsevier Science.

Lakatos, I. (1970). Falsification and the methodology of scientific research programmes. In I. Lakatos \& A. Musgrave (Eds.), Criticisms and the growth of knowledge (pp. 91196). Cambridge, England: Cambridge University Press.

Lang, F. B., Rieckmann, N., \& Baltes, M. M. (2002). Adapting to aging losses: Do resources facilitate strategies of selection, compensation, and optimization in everyday functioning. Journal of Gerontology: Psychological Sciences, 57B, P501-P509.

Li, K. Z. H., Krampe, R. T., \& Bondar, A. (in press). An ecological approach to studying aging and dual-task performance. In R. W. Engle, G. Sedek, U. von Hecker, \& D. N. McIntosh (Eds.), Cognitive limitations in aging and psychopathology. New York: Cambridge University Press.

Li, K. Z. H., Lindenberger, U., Freund, A. M., \& Baltes, P. B. (2001). Walking while memorizing: Age-related differences in compensatory behavior. Psychological Science, 12, 230-237.

Li, S.-C., \& Freund, A. M. (2005). Advances in lifespan psychology: A focus on biocultural and personal influences. Research in Human Development, 2, 1-23.

Li, S.-C., Lindenberger, U., Hommel, B., Aschersleben, G., Prinz, W., \& Baltes, P. B. (2004). Lifespan transformations in the couplings of mental abilities and underlying cognitive processes. Psychological Science, 15, 155-163.

Li, S.-C., Lindenberger, U., \& Sikström, S. (2001). Aging cognition: From neuromodulation to representation. Trends in Cognitive Sciences, 5, 479-486.

Lindenberger, U., Marsiske, M., \& Baltes, P. B. (2000). Memorizing while walking: Increase in dual-task costs from young adulthood to old age. Psychology and Aging, 15, $417-436$.

Lövdén, M., Schellenbach, M., GrossmannHutter, B., Krüger, A., \& Lindenberger, U. (in press). Environmental topography and postural control demands shape agingassociated decrements in spatial navigation performance. Psychology and Aging.

Magnusson, D. (Ed.) (1996). The life span development of individuals: Behavioral, neurobiological, and psychosocial perspectives: A synthesis. Cambridge, UK: Cambridge University Press.

Marsiske, M., Lang, F. B., Baltes, P. B., \& Baltes, M. M. (1995). Selective optimization with compensation: Life-span perspectives on successful human development. In R. A. Dixon \& L. Baeckman (Eds.), Compensating for psychological deficits and declines: Managing losses and promoting gains (pp. 35-79). Mahwah, NJ): Lawrence Erlbaum.

Miller, E. K., \& J. D. Cohen (2001). An integrative theory of prefontal cortex function. Annual Review of Neuroscience, 24, 167-202.

Miller, G. A. (1956). The magical number seven, plus or minus two: Some limits on our capacity for processing information. Psychological Review, 63, 81-97.

Munakata, Y., \& McClelland, J. L. (2003). Connectionist models of development. Developmental Sciences, 6, 413-429. 
Navon, D. (1984). Resources: A theoretical soup stone? Psychological Review, 91, 216-234.

Nieuwenhuis, S., Ridderinkhof, K. R., Talsma, D., Coles, M. G. H., Holroyd, C. B., Kpk, A., \& Van der Molen, M. W. (2002). A computational account of altered error processing in older age: Dopamine and error-related processing. Cognitive, Affective, and Behavioral Neuroscience, 2, 19-36.

Ohnishi, T., Matsuda, H., Tabira, T., Asada, T., \& Uno, M. (2001). Changes in brain morphology in Alzheimer disease and normal aging: Is Alzheimer disease an exaggerated aging process? American Journal of Neuroradiology, 22, 1680-1685.

Pashler, H. (1984). Processing stages in overlapping tasks: Evidence for a central bottleneck. Journal of Experimental Psychology: Human Perception and Performance, 10, 358-377.

Piaget, J. (1980). Les formes élémentaires de la dialectique. Paris: Gallimard.

Piaget, J. (1985). The equilibrium of cognitive structures: The central problem of intellectual development. Chicago: University of Chicago Press.

Quartz, S., \& Sejnowski, T. (2000). Constraining constructivism: cortical and subcortical constraints on learning in development. Behavioral and Brain Sciences, 23, 785-792.

Read, S. J., \& Miller, L. C. (1989). InterPersonalism: Toward a goal-based theory of persons in relationships. In L. A. Pervin (Ed.), Goal concepts in personality and social psychology (pp. 413-472). Hillsdale, NJ: Lawrence Erlbaum.

Riediger, M., \& Freund, A. M. (2004). Interference and facilitation among personal goals: Differential associations with subjective well-being and persistent goal pursuit. Personality and Social Psychology Bulletin, 30, 1511-1523.

Riediger, M., Freund, A. M., \& Baltes, P. B. (2005). Managing life through personal goals: Intergoal facilitation and intensity of goal pursuit in younger and older adulthood. Journal of Gerontology: Psychological Sciences, 60B, P84-P91.

Salthouse, T. A., Rogan, J. D., \& Prill, K. A. (1984). Division of attention: Age differences on a visually presented memory task. Memory and cognition, 12, 613-620.

Sattin, R. W. (1992). Falls among older persons: A public health perspective. Annual Reviews in Public Health, 13, 489-508.

Sirois, S., \& Mareschal, D. (2004). An interacting system model of infant habituation. Journal of Cognitive Neuroscience, 16, 1352-1362.

Smith, L. B., \& Thelen, E. (2003). development as a dynamic system. Trends in Cognitive Sciences, 7, 343-348.

Somberg, B. L., \& Salthouse, T. A. (1982). Divided attention abilities in young and old adults. Journal of Experimental Psychology: Human Perception and Performance, 8, 651-663.

Spencer, W. D., \& Raz, N. (1995). Differential effects of aging on memory for content and context: A meta-analysis. Psychology and Aging, 10, 527-539.

Staudinger, U. M., \& Freund, A. M. (1998). Sick and "poor" in old age and still in good spirits? A study of psychological resilience. Zeitschrift für Klinische Psychologie, Forschung und Praxis, 27, 78-85.

Staudinger, U. M., Freund, A. M., Linden, M., \& Maas, I. (1999). Self, personality, and life regulation: Facets of psychological resilience in old age. In P. B. Baltes \& K. U. Mayer (Eds.), The Berlin Aging Study: Aging from 70 to 100 (pp. 302-328). New York: Cambridge University Press.

Teasdale, N., Bard, C., Dadouchi, F., Fleury, M., LaRue, I., \& Stelmach, G. E. (1992). Posture and elderly persons: Evidence for deficits in the central integrative mechanisms. In G. E. Stelmach \& J. Requin (Eds.), Tutorials in motor behavior II (pp. 917-931). Amsterdam: Elsevier Science.

Teasdale, N., Bard, C., LaRue, J., \& Fleury, M. (1993). On the cognitive penetrability of posture control. Experimental Aging Research, 19, 1-13.

Tinetti, M. E. (1995). Falls. In W. R. Hazzard, E. L. Bierman, J. P. Blass, W. H. Ettinger, \& J. B. Halter (Eds.), Principles of Geriatric Medicine and Gerontology (3rd edition). New York: McGraw-Hill.

Tsang, P. S., \& Shaner, T. L. (1998). Age, attention, expertise, and time-sharing 
performance. Psychology and Aging, 13, 323-347.

von Cranach, M., Ochsenbein, G., \& Valach, L. (1986). The group as a self-active system: Outline of a theory of group action. European Journal of Social Psychology, 16, 193-229.

Vondracek, F. W., \& Porfeli, E. J. (2002). Lifespan developmental perspectives on adult career development: Recent advances. In S. G. Niles (Ed.), Adult career development: Concepts, issues and practices (3rd edition, pp. 20-38). Columbus, OH: National Career Development Association.

Waddington, C. H. (1975). The evolution of an evolutionist. Edinburgh: Edinburgh University Press.

Wegge, J. (2000). Participation in group goal setting: Some novel findings and a comprehensive model as a new ending to an old story. Applied Psychology: An International Review, 49, 498-516.

Wiese, B. S. (2000). On the dynamics of goal structures in the domains of work and partnership. Münster, Germany: Waxmann.

Wiese, B. S., \& Freund, A. M. (2000). The interplay of work and family in young and middle adulthood. In J. Heckhausen (Ed.), Motivational psychology of human development: Developing motivation and motivating development (pp. 233-250). Amsterdam, Netherlands: Elsevier.
Wiese, B. S., Freund, A. M., \& Baltes, P. B. (2000). Selection, optimization, and compensation: An action-related approach to work and partnership. Journal of Vocational Behaviour, 57, 273-300.

Wiese, B. S., Freund, A. M., \& Baltes, P. B. (2002). Subjective career success and emotional well-being: Longitudinal predictive power of selection, optimization, and compensation. Journal of Vocational Behaviour, 60, 321-335.

Wiese, B. S., \& Schmitz, B. (2002). Study-related action in the context of a developmental-psychological meta-model. Zeitschrift für Entwicklungspsychologie und Pädagogische Psychologie, 34, 80-94.

Wilensky, R. (1983). Planning and Understanding. Reading, MA: Addison-Wesley.

Woollacott, M. H. (2000). Systems contributing to balance disorders in older adults. Journal of Gerontology: Medical Sciences, 55A, M424-M+28.

Woollacott, M. H., \& Shumway-Cook, A. (2002). Attention and the control of posture and gait: A review of an emerging area of research. Gait and Posture, 16, 1-14.

Wrosch, C., \& Heckhausen, J. (1999). Control processes before and after passing a developmental deadline: Activation and deactivation of intimate relationship goals. lournal of Personality and Social Psychology. 77. 415-427. 